Sains Malaysiana 49(10)(2020): 2573-2585

http://dx.doi.org/10.17576/jsm-2020-4910-23

\title{
Analisis Penskalaan bagi Kejadian Hujan Ekstrim di Semenanjung Malaysia
}

(Scaling Analysis for Extreme Rainfall Events in Peninsular Malaysia)

\author{
WAN ZAWIAH WAN ZIN*, ABDUL AZIZ JEMAIN, MARINA ZAHARI \& KAMARULZAMAN IBRAHIM
}

\begin{abstract}
ABSTRAK
Maklumat mengenai kehujanan ekstrim dalam skala masa berbeza diperlukan dalam pembinaan lengkuk keamatantempoh-kekerapan (IDF). IDF menjadi rujukan utama dalam pembinaan infrastruktur berkaitan hujan seperti sistem perparitan dan empangan. Seringkali, agak sukar untuk mendapatkan data dalam pelbagai skala seperti per minit, per jam dan per hari. Justeru, kajian ini menggunakan konsep penskalaan yang mengambil kira sifat kebersandaran antara data hujan ekstrim pada sub skala yang berbeza dalam mengkaji ciri-ciri hujan ekstrim. Dalam kajian ini, data hujan maksimum dalam tempoh sejam sehingga 48 jam dari tahun 1970-2008 di 43 buah stesen cerapan hujan di Semenanjung Malaysia telah diuji. Penentuan jenis penskalaan yang sesuai; sama ada penskalaan ringkas atau pelbagai diuji berdasarkan teori skala tak varians. Hasil mendapati bahawa 41 stesen kajian memenuhi syarat penskalaan ringkas dan seterusnya, faktor penskalaan eksponen bagi setiap stesen telah ditentukan. Ini diikuti dengan pemadanan taburan ekstrim yang paling sesuai dengan data kajian bagi setiap stesen memandangkan konsep pembangunan IDF berasaskan taburan statistik. Lima taburan ekstrim iaitu taburan Ekstrim Teritlak (GEV), Logistik Teritlak (GLO), Gumbel, Pareto Teritlak (GPA) dan Pearson 3-Parameter (P3) telah dipadankan kepada data hujan maksimum harian dan hasil mendapati padanan data dengan GEV dan GLO di kebanyakan stesen. Berdasarkan maklumat taburan terbaik, nilai-nilai ulangan dihitung untuk pelbagai skala masa dengan menggunakan maklumat daripada hanya satu skala masa sahaja. Hasil kajian ini ternyata membolehkan pengurusan data yang lebih cekap dalam pembangunan IDF kerana data daripada hanya satu skala masa sahaja sudah mencukupi untuk menganggar nilai pada skala masa yang berlainan.
\end{abstract}

Kata kunci: IDF; konsep penskalaan; lengkung keamatan-tempoh-kekerapan; taburan nilai ekstrim

\section{ABSTRACT}

Information on extreme rainfall at various time scales is needed in the construction of the Intensity-DurationFrequency (IDF) curve. Thus, the concept of scaling which takes into account of the dependency property of extreme rainfall data at various time scales in studying the characteristics of extreme rainfall is investigated in this study. Maximum rainfall data in the scales of one-hour until 48-hour for the years 1970 to 2008 at 43 rain-gauge stations were analyzed. The determination of the suitable type of scaling, either the simple scaling or multi-scaling, was tested based on the scale-invariance property. The result shows that 41 stations satisfied the simple scaling property and the scaling exponent for each station was determined. IDF concept requires data to be fitted by a suitable statistical distribution, thus, five types of extreme distributions, namely the Generalised Extreme Values (GEV), Generalised Logistic (GLO), Gumbel, Generalised Pareto (GPA) and Pearson 3-Parameter (P3) were fitted to the maximum daily rainfall data and the results showed that most stations followed the GEV and GLO. Subsequently, based on the bestfitted distribution for each station and the estimated scaling factor, the return values for various time scales at each station can be calculated using information from only one time scale. The results of this study will enable the efficient management of data in the development of IDF as it only requires data from one time scale to estimate values at various other time scales.

Keywords: Extreme value distribution; intensity-duration-frequency curve; IDF; scaling concept

\section{INTRODUCTION}

Dalam analisis cuaca ekstrim khususnya yang melibatkan data hujan, data yang tepat dalam skala pelbagai adalah penting dan diperlukan bagi situasi yang berbeza. Sebagai contoh, data amaun hujan pada skala yang pendek (1 atau
3 jam) sesuai dalam analisis bagi kesan kelebatan hujan dalam jangka masa yang pendek. Sebaliknya, dalam kes analisis banjir besar, data amaun hujan dalam skala masa yang panjang lebih bertepatan (24 jam). Oleh yang demikian, adalah penting sekiranya data amaun hujan 
dalam tempoh yang berbeza dapat diperoleh. Keperluan untuk analisis data hujan dalam pelbagai skala masa telah dikaji dalam kajian oleh Blöschl dan Sivapalan (1995), Rodriguez-Iturbe et al. (1984) dan Westra et al. (2014) dengan tumpuan kajian mengenai hubungan ciri-ciri hujan ekstrim pada skala yang berbeza.

IDF merupakan sebuah alat piawai untuk reka bentuk hidraulik dan analisis risiko memandangkan lengkuk ini menjelaskan hubungan antara frekuensi keberlakuan keamatan hujan ekstrim dalam beberapa tempoh masa. Ia menjadi rujukan jurutera awam dalam perancangan kerja pembinaan infrastruktur berkaitan dengan kehujanan seperti empangan dan parit. Lengkuk ini dibina dengan melakukan analisis statistik ke atas sama ada data daripada siri maksimum hujan atau siri puncak melangkaui ambang dengan memadankan beberapa lengkuk dengan taburan kebarangkalian yang sesuai untuk beberapa tempoh masa kehujanan (Bougadis \& Adamowski 2006). Dalam sesebuah plot IDF, bergantung kepada keperluan hidrologi, nilai ulangan, $T$ tahun disukat mengikut tempoh hujan, contohnya nilai ulangan $T$ tahun skala harian (24 jam), 12, 3, 1 atau sebarangan sub-jam. Penganggaran yang tepat diperlukan kerana penganggaran yang kurang boleh mengakibatkan kerosakan pada struktur binaan manakala penganggaran yang lebih mengakibatkan pembaziran dari segi kos (Ellouze \& Abida 2008). Maka, sumber data yang setepat mungkin perlu digunakan bagi memastikan lengkuk IDF yang dihasilkan kurang ralat dalam nilai yang dihasilkan.

Sifat kehujanan adalah bersandar dengan hujan dalam skala masa yang panjang (contohnya 24 jam) sebenarnya merupakan nilai kumulatif amaun hujan pada skala masa yang lebih pendek (jumlah hujan dalam tempoh 24-jam berkenaan). Dalam erti-kata lain, amaun hujan ekstrim sesuatu sub-skalaan adalah penyepaduan subskala yang lebih kecil, sebagai contoh skala 12 jam merupakan penyepaduan subskala satu jam yang membentuk skala dua jam, empat jam dan seterusnya. Ini bermakna tingkah laku kerawakan pada suatu subskala mempengaruhi tingkah laku pada subskala yang lebih besar. Mengambil kira sifat kebersandaran ini, kaedah penskalaan boleh digunakan dalam kes bila masa data sebenar nilai hujan pada sesuatu skala masa tidak dapat diperoleh. Seterusnya dari aspek penerapan, penganggaran nilai ulangan dihitung dengan mengambil kira maklumat ini. Beberapa kajian seperti oleh Bougadis dan Adamowski (2006) serta Burlando dan Rosso (1996) telah membincangkan mengenai teknik penskalaan manakala kajian oleh Rahman (2015) di Bangladesh, Rana et al. (2013) di India, Agbazo et al. (2016) di Afrika Selatan, Menabde et al. (1999) di Australia dan Bara et al. (2010) di Slovakia telah menerapkan kaedah penskalaan kepada data hujan sebenar di kawasan masing-masing. Nilai faktor penskalaan yang diperoleh boleh digunakan untuk penurunan skala (downscaling) atau penambahan skala (upscaling) dalam mendapatkan nilai anggaran hujan pada sesuatu masa untuk pembinaan keluk IDF atau lain-lain tujuan.

Kajian ini menfokuskan kepada 43 stesen cerapan hujan di Semenanjung Malaysia. Kaedah penskalaan telah digunakan ke atas setiap stesen bagi memeriksa jenis penskalaan yang lebih sesuai; sama ada penskalaan ringkas atau berbilang. Seterusnya, lima taburan ekstrim yang sesuai bagi data hujan maksimum tahunan dalam skala 24-jam dipadankan kepada kesemua stesen untuk mendapatkan taburan terbaik dalam mewakili kejadian hujan ekstrim di stesen berkenaan. Akhir sekali, nilai ulangan bagi beberapa tempoh ulangan dihitung bagi mendapatkan nilai hujan ekstrim yang mungkin pada tempoh masa hadapan yang diperlukan dalam pembangunan IDF. Menggunakan faktor penskalaan yang telah diperoleh, nilai ulangan bagi skala masa yang berlainan boleh dihitung secara lansung dengan hanya menggunakan maklumat daripada satu skala masa. Setakat kajian kepustakaan yang telah dijalankan, tiada lagi kajian di Malaysia yang menggunakan teknik penskalaan ke atas skala masa yang berbeza bagi data hujan pernah diterbitkan sebelum ini. Kajian sebelum ini yang telah dijalankan ke atas data hujan ekstrim di Malaysia lebih tertumpu kepada pemadanan taburan seperti kajian oleh Eli et al. (2012) dan Zin et al. (2009), trend kehujanan oleh Deni et al. (2009), Halim et al. (2015), Hanawi et al. (2011) dan Zin et al. (2010).

\section{TEORI TAKVARIANS SKALA}

Model penskalaan berdasarkan konsep takvarians skala (Dubrulle et al. 1997) telah dicadangkan untuk menghubungkan ciri hujan pada masa yang berbeza. Katalah $X_{d}, X_{d o}$ masing-masing adalah amaun rawak dua skala berbeza, $d$ dan $d_{o}$ dengan kedua-dua skala $d$ dan $d_{o}$ terkandung dalam suatu selangan skala $\left[D_{b}, D_{a}\right]$. Sebagai contoh, katakan pemboleh ubah $X$ adalah amaun hujan maksimum tahunan, $d=12$ jam dan $d_{o}=24$ jam bagi suatu subskala $\left[D_{b}=1, D_{a}=48\right]$ jam. Nilai rawak yang memenuhi ciri takvarians skala mempunyai fungsi taburan yang secaman seperti berikut (Menabde et al. 1999; Yu et al. 2004):

$$
X_{d} \stackrel{d}{=}\left(\frac{d}{d_{o}}\right)^{\alpha} X_{d_{o}}
$$

Tanda = bermaksud mempunyai taburan yang sama dan $\alpha$ faktor eksponen. Hubungan tersebut mengakibatkan momen ke-r bagi kedua-dua skala memiliki kesamaan berikut,

$$
E\left(X_{d}^{r}\right)=\left(\frac{d}{d_{o}}\right)^{\alpha_{r}} E\left(X_{d_{o}}^{r}\right)
$$

Dengan mengambil nilai ln untuk hubungan ini, maka

$$
\ln \left(E\left(X_{d}^{r}\right)\right)=\alpha_{r} \ln \left(\frac{d}{d_{o}}\right)+\ln \left(E\left(X_{d_{o}}^{r}\right)\right)
$$


Ungkapan ini menatijahkan yang graf $\ln \left(E\left(X_{d}^{r}\right)\right)$ lawan $\ln \left(\frac{d}{d_{o}}\right)$ bagi suatu nilai momen $r$ miliki bentuk linear dengan kecerunan $\alpha_{r}$. Seterusnya dengan mengumpulkan kecerunan untuk pelbagai momen $r$ yang berbeza, sebuah graf $\alpha_{r}$ lawan $r$ dapat dibina. Sekiranya graf yang terhasil berbentuk linear dengan kecerunan malar bersamaan $\alpha$, sifat takvarians skala dikenali sebagai skala tunggal ringkas, sebaliknya jika graf yang terhasil tidak linear sifat skala dikenali sebagai multiskala. Model skala tunggal lebih digemari kerana bilangan parameter yang diperlukan lebih kecil berbanding model multiskala yang melibatkan lebih banyak faktor pendaraban dalam modelnya (Burlando \& Rosso 1996; Gupta \& Waymire 1990; Langousis et al. 2013; Lovejoy \& Schertzer 1985; Veneziano \& Furcolo 2002; Veneziano \& Langousis 2010). Dalam model penskalaan ringkas, sebuah eksponen, $\mathrm{H}$, digunakan untuk mencirikan taburan hujan ekstrim pada kesemua skala yang memenuhi ciri takvarians. Justeru, anggaran yang lebih tekal untuk nilai hujan ekstrim boleh diperoleh walaupun pada masa data yang tidak diperoleh sebelum ini membolehkan pembangunan IDF lebih mudah dilakukan (Burlando \& Rosso 1996; Ceresetti 2010; De Michele et al. 2001; Menabde et al. 1999).

\section{NILAI ULANGAN PELBAGAI SKALA}

Dengan memilih suatu skala rujukan, sebagai contoh skala harian (24 jam), nilai ulangan untuk subskala yang lain yang bersesuaian dianggar menggunakan sifat skala takvarians. Dengan menggunakan hubungan kesecaman taburan pada persamaan (1), nilai ulangan $X_{d, T}$ pada $\mathrm{T}$ tahun untuk skala $d$, adalah seperti berikut:

$$
K b\left(X_{d} \geq x_{d, T}\right)=K b\left(\left(\frac{d}{d_{o}}\right)^{\alpha} X_{d_{o}} \geq x_{d, T}\right)=\frac{1}{T}
$$

atau dapat juga ditulis semula sebagai

$$
K b\left(X_{d} \leq x_{d, T}\right)=K b\left(X_{d_{o}} \leq\left(\frac{d_{o}}{d}\right)^{\alpha} x_{d, T}\right)=1-\frac{1}{T}
$$

Jika $F_{d}(x)$ mewakili fungsi taburan bagi pemboleh ubah rawak $X$ untuk skala tertentu $d$, maka hubungan berikut dihasilkan

$$
F_{d}\left(x_{d, T}\right)=F_{d_{o}}\left(\left(\frac{d_{o}}{d}\right)^{\alpha} x_{d, T}\right)=1-\frac{1}{T}
$$

Dapat disimpulkan yang

$$
x_{d, T}=\left(\frac{d}{d_{o}}\right)^{\alpha} F_{d_{o}}^{-1}\left(1-\frac{1}{T}\right)
$$

Dalam erti kata lain, dengan memilih suatu skala sebagai rujukan dan menganalisis data yang berkaitan dengan skala pilihan dan fungsi taburan yang bersesuaian, nilai-nilai ulangan pada tempoh $\mathrm{T}$ tertentu dapat dianggarkan.

\section{TABURAN NILAI EKSTRIM}

Beberapa taburan ekstrim yang sering digunakan dalam kajian hujan ekstrim diguna pakai dalam kajian ini untuk menentukan taburan yang paling sesuai bagi setiap stesen. Taburan berkenaan ialah taburan Nilai Ekstrim Teritlak (GEV), Logistik Teritlak (GLO), Pareto Teritlak (GPA), Gumbel dan Pearson-III (P3). Persamaan bagi fungsi ketumpatan kumulatif, $F(x)$ dan nilai ulangan, $x_{T}$ bagi tempoh ulangan, $T$ untuk setiap taburan (kecuali bagi P3 merupakan fungsi ketumpatan kebarangkalian, $f(x)$ ) yang dipadankan pada data kajian dinyatakan dalam Jadual 1

\begin{tabular}{|c|c|c|c|}
\hline No. & Taburan & Fungsi Kumulatif Ketumpatan, $F(x)$ & Nilai Ulangan, $x_{T}$ \\
\hline 1 & GEV & $\exp (-\exp (-y))$ & $\xi+\frac{\delta}{\kappa}\left(1-\left(-\log \left(1-\frac{1}{T}\right)\right)^{\kappa}\right.$ \\
\hline 2 & GLO & & $\xi+\frac{\delta}{\kappa}\left(1-\left(\frac{1}{1-T}\right)^{\kappa}\right)$ \\
\hline 3 & Gumbel & $\exp \left(-\exp \left(-\frac{1}{\alpha}(x-\xi)\right)\right)$ & $\xi-\delta \log \left(-\log \left(1-\frac{1}{T}\right)\right.$ \\
\hline 4 & GPA & $1-\exp (-y)$ & $\xi+\frac{\delta}{\kappa}\left(1-\left(\frac{1}{T}\right)^{\kappa}\right)$ \\
\hline 5 & P3 & $f_{P 3}(x ; \xi, \delta, \kappa)=\frac{1}{\alpha \Gamma(\kappa)}\left(\frac{x-\xi}{\alpha}\right)^{\kappa-1} \exp \left(-\frac{x-\xi}{\alpha}\right)$ & $\xi+\delta F_{P 3}^{-1}\left(1-\frac{1}{T} ; 1, \kappa, 0\right)$ \\
\hline
\end{tabular}
dengan $\xi$ mewakili parameter lokasi, $\delta$ parameter skala dan $\kappa$ parameter bentuk:

JADUAL 1. Senarai taburan yang digunakan dalam kajian ini

dengan $y=-\frac{1}{\kappa} \log \left(1-\frac{\kappa}{\delta}(x-\xi)\right)$ 
Dalam kajian ini, kaedah L-momen (LMOM) digunakan untuk menganggar parameter bagi taburan nilai ekstrim yang dikaji. Kaedah LMOM yang diperkenalkan oleh Hosking (1990) telah digunakan dengan meluas dalam pelbagai bidang seperti insurans, hidrologi dan kejuruteraan dalam mendapatkan nilai-nilai parameter. Kaedah ini berdasarkan gabungan statistik tertib dengan statistik tertib pertama sehingga ke empat masingmasing mewakili sukatan lokasi, skala, kepencongan dan kurtosis. Vogel dan Fennessey (1993) mencadangkan penggunaan LMOM kerana sifat teguhnya dan boleh digunakan walaupun saiz sampel agak kecil.

Misalkan $X_{1}, X_{2}, \ldots . ., X_{r}$ ialah sampel rawak saiz $r$ yang mempunyai fungsi ketumpatan kebarangkalian $f(x)$. Momen ke- $r$ bagi LMOM, $\lambda_{r}$ ditakrifkan sebagai:

$$
\lambda_{r}=\frac{1}{r} \sum_{k=0}^{r-1}(-1)^{k}\left(\begin{array}{l}
r-1 \\
k
\end{array}\right)^{\alpha_{r}} E\left(X_{r-k: r}\right) ; \quad r=1,2, \ldots
$$

dengan $X_{1-k: r}$ merupakan pemboleh ubah rawak untuk statistik tertib ke $(r-k)$. Sifat L-momen menyatakan bahawa nilai momen ke- $r$ ini boleh dibandingkan dengan nilai empirik momen daripada taburan untuk mendapatkan parameter taburan; sebagai contoh momen pertama, $\lambda_{1}$ boleh mewakili jangkaan taburan manakala $\lambda_{2}$ adalah skala taburan. Hosking (1990) mencadangkan agar $\lambda_{1}$ yakni L-kedudukan berkait dengan momen pertama taburan, $\lambda_{2}$ iaitu L-skala, bersamaan dengan sisihan piawai, $\tau=\lambda_{2} / \lambda_{1}$ merujuk kepada L-pekali variasi (L$\mathrm{Cv})$ bersamaan dengan pekali variasi taburan manakala $\tau_{3}=\lambda_{3} / \lambda_{2}$ (L-kepencongan) dan $\tau_{4}=\lambda_{4} / \lambda_{2}$ (L-Kurtosis) masing-masing boleh disama-ertikan dengan nilai kepencongan dan kurtosis sesebuah taburan.

Dalam menentukan taburan terbaik, ujian kebagusan penyuaian Min Ralat Mutlak, MRM, digunakan. Katalah $x_{i: n}$ merupakan data yang mewakili cerapan tertib ke- $i$ daripada sejumlah $n$ cerapan dan $F(x ; \hat{\theta})$ adalah taburan pemadanan dengan $\hat{\theta}$ anggaran vektor parameter taburan, maka, ralat yang sepadan dengan cerapan tertib ke- $i$ adalah

$$
\varepsilon_{i: n}=x_{i: n}-\hat{x}_{i: n} \text { dengan } \hat{x}_{i: n}=F^{-1}\left(\frac{i}{n+1} ; \hat{\theta}\right)
$$

Ralat yang diperoleh boleh digunakan sebagai sukatan kebagusan penganggar, dan penunjuk kebagusan pemadanan yang digunakan dalam kajian ini ialah Min Ralat Mutlak, MRM yang diwakili oleh:

$$
\mathrm{MRM}=\frac{1}{n} \sum_{i=1}^{n}\left|\frac{x_{i: n}-\hat{Q}\left(F_{i}\right)}{x_{i: n}}\right|
$$

PENERAPAN EMPERIK CIRI TAKVARIANS SKALA

Dalam kajian ini, data hujan ekstrim di Semenanjung Malaysia pada tahun 1970 sehingga tahun 2008 digunakan. Sebagai illustrasi pengiraan, sampel data bagi stesen hujan Johor Bharu dan Kota Tinggi melibatkan cerapan amaun hujan maksimum berdasarkan lima subskala tempoh hujan bagi tingkap tempoh hujan 1, 6, 12, 24 dan 48 jam dibentangkan pada Jadual 2. Menggunakan rumus (3), nilai log momen untuk $r=1,2, \ldots, 5$ untuk setiap skala disenaraikan dalam jadual dengan rumus diberikan di bawah Jadual 2.

\begin{tabular}{|c|c|c|c|c|c|c|c|c|c|c|}
\hline & \multicolumn{5}{|c|}{ Johor Bahru } & \multicolumn{5}{|c|}{ Kota Tinggi } \\
\hline & \multicolumn{10}{|c|}{ Tempoh (jam) } \\
\hline & 1 & 6 & 12 & 24 & 48 & 1 & 6 & 12 & 24 & 48 \\
\hline \multicolumn{11}{|c|}{ Sampel data } \\
\hline 1974 & 50.0 & 90.9 & 90.9 & 97.9 & 113.9 & 32.4 & 57.8 & 58.6 & 67.6 & 86.6 \\
\hline 1975 & 82.8 & 124.0 & 138.0 & 138.0 & 145.5 & 59.8 & 69.8 & 93.0 & 93.0 & 105.5 \\
\hline 1976 & 66.7 & 84.6 & 84.6 & 84.6 & 122.6 & 40.4 & 65.7 & 67.4 & 80.5 & 87.0 \\
\hline \multicolumn{11}{|l|}{$\cdots$} \\
\hline 2006 & 72.5 & 156.2 & 200.6 & 285.4 & 343.4 & 74.0 & 74.5 & 85.0 & 85.4 & 93.1 \\
\hline 2007 & 68.0 & 167.6 & 180.2 & 226.9 & 339.3 & 55.3 & 91.2 & 103.0 & 104.9 & 104.9 \\
\hline 2008 & 67.8 & 85.1 & 113.6 & 116.1 & 203.9 & 63.6 & 89.7 & 97.5 & 113.6 & 114.1 \\
\hline
\end{tabular}

JADUAL 2. Amaun hujan maksimum dan anggaran log momen yang berkaitan untuk tempoh 1 ke 48 jam bagi Stesen Johor Bahru dan Stesen Kota Tinggi 


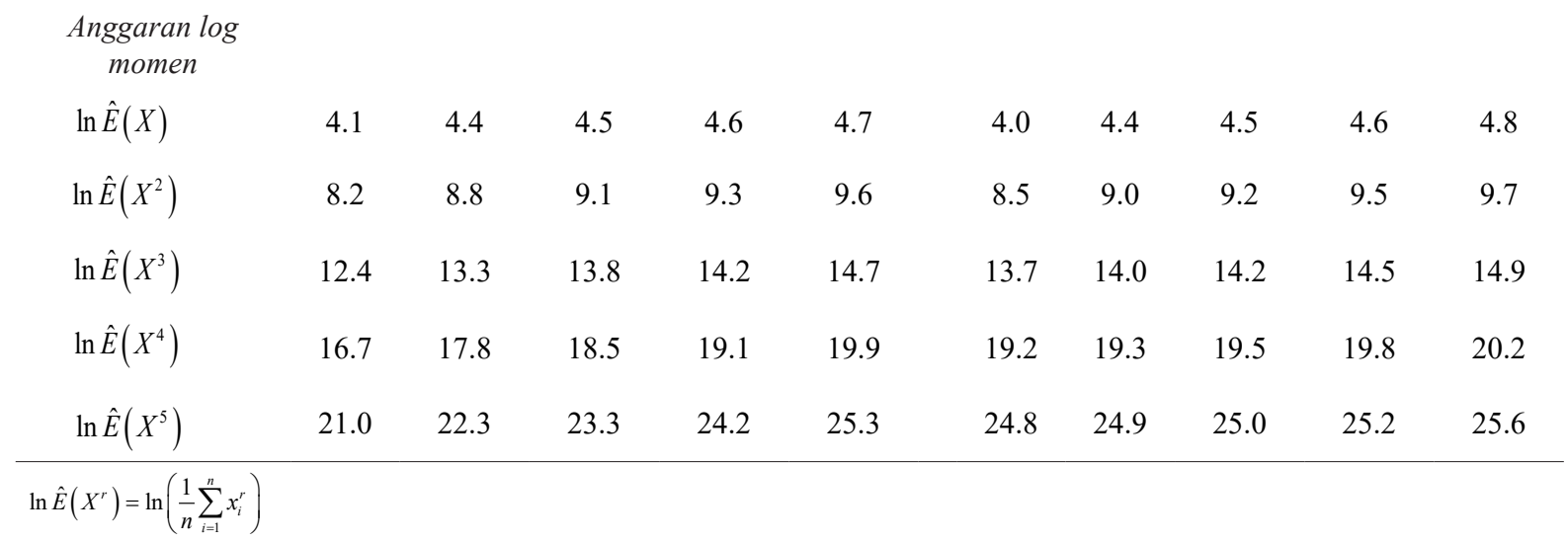

Kesesuaian sifat penskalaan ringkas terhadap data boleh disemak melalui momen tertib seperti dalam persamaan (2) dan nilai anggaran $R^{2}$ dalam Jadual 3. Hasil menunjukkan bahawa nilai $R^{2}$ melebihi 0.99 bagi kesemua stesen kecuali Stesen Kota Tinggi dan Stesen Sawah Lebar; dengan nilai $R^{2}$ masing-masing adalah 0.83 dan 0.94 . Keputusan $R^{2}$ ini adalah konsisten dengan plot kecerunan log momen/tempoh melawan tertib (Momen) seperti dalam Rajah 1 bagi stesen 2-10. Dapat dilihat bahawa kesemua momen bagi stesen-stesen berkenaan adalah berada pada suatu garis lurus; menunjukkan ujian untuk penentuan penskalaan ringkas dipenuhi kecuali di Stesen Kota Tinggi (Stesen 2) dan Stesen Sawah Lebar (Stesen 9) yang mempamerkan garis tidak linear. Ini bermaksud bahawa sifat penskalaan ringkas tidak dipenuhi untuk kedua-dua stesen ini.

JADUAL 3. Nilai-nilai kecerunan momen pertama sehingga kelima, faktor skala dan nilai bagi semua stesen hujan di Semenanjung Malaysia

\begin{tabular}{cccccccc}
\hline Stesen & $\mathrm{m} 1$ & $\mathrm{~m} 2$ & $\mathrm{~m} 3$ & $\mathrm{~m} 4$ & $\mathrm{~m} 5$ & Faktor Skala & Nilai R $^{2}$ \\
\hline Johor Bahru & 0.2088 & 0.4542 & 0.7506 & 1.0984 & 1.4832 & 0.2760 & 0.9909 \\
Kota Tinggi & 0.2177 & 0.3809 & 0.4316 & 0.3985 & 0.3400 & - & 0.8289 \\
Mersing & 0.3220 & 0.6770 & 1.0555 & 1.4483 & 1.8483 & 0.3614 & 0.9989 \\
Endau & 0.4120 & 0.8430 & 1.2818 & 1.7229 & 2.1640 & 0.4301 & 0.9999 \\
Labis & 0.2654 & 0.5699 & 0.8960 & 1.2235 & 1.5407 & 0.3035 & 0.9991 \\
Chin Chin & 0.1410 & 0.2847 & 0.4336 & 0.5902 & 0.7558 & 0.1482 & 0.9994 \\
Sg. Udang & 0.1400 & 0.2879 & 0.4443 & 0.6087 & 0.7806 & 0.1525 & 0.9991 \\
Rompin & 0.1787 & 0.3597 & 0.5474 & 0.7362 & 0.9180 & 0.1832 & 0.9999 \\
Sawah Lebar & 0.1451 & 0.2712 & 0.3564 & 0.3874 & 0.3770 & - & 0.9420 \\
Seremban & 0.1673 & 0.3334 & 0.4984 & 0.6627 & 0.8266 & 0.1657 & 1.0000 \\
Sg. Manggis & 0.1361 & 0.2781 & 0.4298 & 0.5941 & 0.7711 & 0.1493 & 0.9984 \\
Semenyih & 0.1574 & 0.3386 & 0.5579 & 0.8233 & 1.1291 & 0.2081 & 0.9891 \\
Kuala Klawang & 0.1676 & 0.3414 & 0.5268 & 0.7232 & 0.9244 & 0.1808 & 0.9991 \\
Sg. Kepasing & 0.2095 & 0.4316 & 0.6655 & 0.9090 & 1.1584 & 0.2272 & 0.9993 \\
Ampang & 0.1322 & 0.2635 & 0.3956 & 0.5302 & 0.6689 & 0.1329 & 1.0000 \\
Edinburgh & 0.1379 & 0.2808 & 0.4307 & 0.5894 & 0.7576 & 0.1479 & 0.9991 \\
Genting Klang & 0.1659 & 0.3420 & 0.5403 & 0.7703 & 1.0293 & 0.1945 & 0.9951 \\
Kuala Sleh & 0.1446 & 0.2953 & 0.4529 & 0.6184 & 0.7924 & 0.1551 & 0.9993 \\
Gombak & 0.1469 & 0.2880 & 0.4221 & 0.5472 & 0.6616 & 0.1361 & 0.9989 \\
Sg. Tua & 0.1560 & 0.3140 & 0.4777 & 0.6494 & 0.8290 & 0.1629 & 0.9996 \\
Pekan & 0.3669 & 0.7796 & 1.2201 & 1.6738 & 2.1327 & 0.4172 & 0.9989
\end{tabular}




\begin{tabular}{clllllll} 
Kalong Tengah & 0.1964 & 0.3934 & 0.5931 & 0.7978 & 1.0095 & 0.2000 & 0.9999 \\
Tanjung Malim & 0.1629 & 0.3214 & 0.4791 & 0.6382 & 0.8001 & 0.1599 & 1.0000 \\
Sg. Bernam & 0.1406 & 0.2885 & 0.4453 & 0.6119 & 0.7887 & 0.1535 & 0.9989 \\
Paya Kangsar & 0.1742 & 0.3371 & 0.4924 & 0.6450 & 0.8000 & 0.1619 & 0.9996 \\
Ulu Tekai & 0.3128 & 0.6706 & 1.0684 & 1.4878 & 1.9119 & 0.3704 & 0.9977 \\
Bikam & 0.1717 & 0.3462 & 0.5245 & 0.7065 & 0.8917 & 0.1768 & 0.9999 \\
Telok Intan & 0.1832 & 0.3712 & 0.5639 & 0.7590 & 0.9541 & 0.1895 & 0.9999 \\
Sitiawan & 0.1364 & 0.2629 & 0.3836 & 0.5061 & 0.6374 & 0.1277 & 0.9998 \\
Kampar & 0.1765 & 0.3530 & 0.5293 & 0.7055 & 0.8818 & 0.1764 & 1.0000 \\
Dungun & 0.3825 & 0.8108 & 1.2966 & 1.8372 & 2.4112 & 0.4600 & 0.9960 \\
Dura & 0.4103 & 0.8698 & 1.3670 & 1.8950 & 2.4459 & 0.4738 & 0.9981 \\
Gua Musang & 0.1838 & 0.3808 & 0.5960 & 0.8327 & 1.0909 & 0.2094 & 0.9974 \\
Bertam & 0.1911 & 0.3946 & 0.6121 & 0.8467 & 1.0979 & 0.2126 & 0.9983 \\
Sg. Tong & 0.3850 & 0.8038 & 1.2473 & 1.7089 & 2.1826 & 0.4270 & 0.9990 \\
Chalok & 0.4234 & 0.8698 & 1.3306 & 1.8007 & 2.2773 & 0.4499 & 0.9997 \\
Dabong & 0.2805 & 0.5737 & 0.8806 & 1.1969 & 1.5166 & 0.2989 & 0.9996 \\
Sg. Pinang & 0.2693 & 0.5532 & 0.8519 & 1.1647 & 1.4896 & 0.2916 & 0.9992 \\
Bkt. Bendera & 0.2629 & 0.5440 & 0.8384 & 1.1412 & 1.4481 & 0.2849 & 0.9994 \\
Baling & 0.1922 & 0.3795 & 0.5715 & 0.7706 & 0.9767 & 0.1933 & 0.9999 \\
Jeniang Klinik & 0.3850 & 0.8038 & 1.2473 & 1.7089 & 2.1826 & 0.4270 & 0.9990 \\
Alor Setar & 0.2156 & 0.4436 & 0.6849 & 0.9402 & 1.2086 & 0.2357 & 0.9989 \\
Kuala Nerang & 0.1364 & 0.2629 & 0.3836 & 0.5061 & 0.6374 & 0.1277 & 0.9998 \\
\hline
\end{tabular}
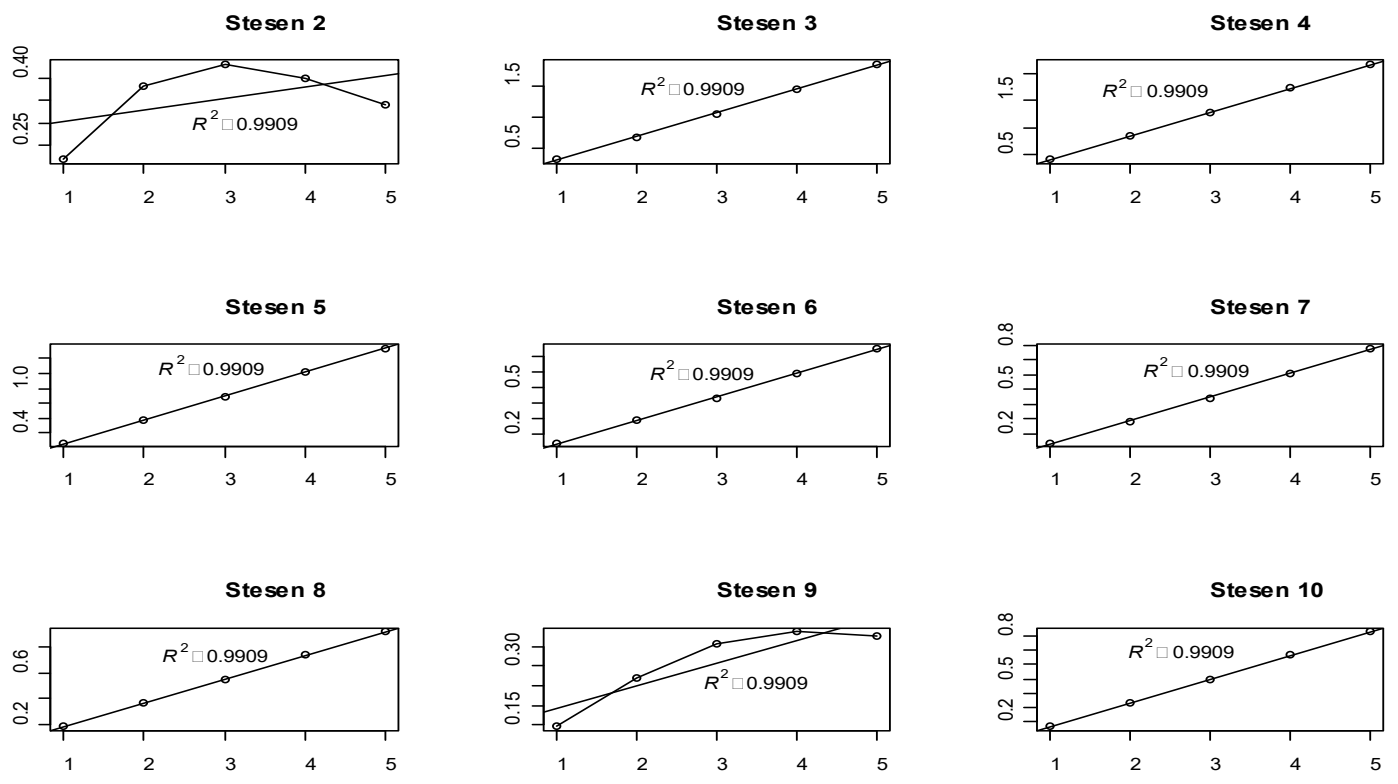

RAJAH 1. Plot Kecerunan log momen/tempoh melawan tertib (Momen) bagi Stesen 2 - Stesen 10 
Langkah seterusnya ialah pemadanan taburan terbaik untuk data amaun hujan ekstrim harian (24-jam) bagi setiap stesen kajian. Lima taburan ekstrim akan dipadankan terhadap data amaun hujan ekstrim dengan parameter taburan dianggar menggunakan kaedah L-momen. Taburan terbaik bagi setiap stesen diputuskan berasaskan ralat kebagusan pemadanan (MRM) seperti dalam (9). Jadual 4 menunjukkan taburan GLO mempunyai pemadanan yang paling baik dalam kalangan stesen-stesen kajian, iaitu sebanyak 16 stesen (37\%), diikuti dengan taburan GEV sebanyak 10 buah stesen $(23 \%)$, taburan GPA dan P3, masing-masing lapan stesen (19\%). Hanya satu stesen (Edinburgh yang terletak di kawasan selatan Malaysia) dapat dipadankan dengan baik menggunakan taburan Gumbel.

JADUAL 4. Peratusan ralat mengikut taburan yang dipadankan

\begin{tabular}{|c|c|c|c|c|c|}
\hline Stesen hujan & GLO & GEV & Gumbel & GPA & P3 \\
\hline Johor Bahru & $6.392^{*}$ & 7.044 & 7.859 & 9.184 & 8.131 \\
\hline Kota Tinggi & 5.758 & 4.876 & 7.592 & $3.720^{*}$ & 3.721 \\
\hline Mersing & 4.992 & 4.102 & 4.093 & 4.365 & $3.961^{*}$ \\
\hline Endau & 4.071 & $3.119^{*}$ & 5.38 & 4.338 & 3.189 \\
\hline Labis & 7.44 & 6.396 & 6.566 & $5.026^{*}$ & 5.710 \\
\hline Chin Chin & 3.509 & 2.734 & 3.07 & $1.895^{*}$ & 2.664 \\
\hline Sg. Udang & $5.176^{*}$ & 5.855 & 7.697 & 8.008 & 5.549 \\
\hline Rompin & $3.692^{*}$ & 3.909 & 3.778 & 5.608 & 4.165 \\
\hline Sawah Lebar & 3.649 & 3.090 & 4.619 & 3.104 & $2.911^{*}$ \\
\hline Seremban & 2.562 & $2.113^{*}$ & 2.569 & 3.052 & 2.154 \\
\hline Sg. Manggis & 2.937 & $2.849^{*}$ & 3.738 & 3.930 & 3.226 \\
\hline Semenyih & $4.694^{*}$ & 5.345 & 5.344 & 7.424 & 5.829 \\
\hline Kuala Klawang & $5.782^{*}$ & 5.979 & 7.579 & 7.248 & 7.104 \\
\hline Sg. Kepasing & $5.831^{*}$ & 6.612 & 6.880 & 9.131 & 6.435 \\
\hline Ampang & 2.547 & 1.958 & 3.328 & $1.886^{*}$ & 2.021 \\
\hline Edinburgh & 3.784 & 3.548 & $3.469^{*}$ & 4.222 & 3.561 \\
\hline Genting Klang & $6.058^{*}$ & 6.437 & 6.214 & 8.071 & 6.820 \\
\hline Kuala Sleh & $5.441^{*}$ & 6.340 & 6.552 & 8.303 & 6.376 \\
\hline Gombak & $2.717^{*}$ & 3.041 & 2.983 & 4.453 & 3.262 \\
\hline Sg. Tua & 2.840 & $2.789^{*}$ & 3.377 & 3.404 & 3.032 \\
\hline Pekan & 6.822 & 5.710 & 8.109 & 5.458 & $5.298^{*}$ \\
\hline Kalong Tengah & $3.584^{*}$ & 3.927 & 4.157 & 5.625 & 4.619 \\
\hline Tanjung Malim & $3.431^{*}$ & 3.823 & 4.266 & 5.666 & 3.870 \\
\hline Sg. Bernam & 2.913 & $2.635^{*}$ & 3.858 & 2.929 & $2.760^{*}$ \\
\hline Paya Kangsar & 3.444 & $2.850^{*}$ & 3.312 & 3.521 & 2.907 \\
\hline Ulu Tekai & 7.521 & $7.298^{*}$ & 9.518 & 8.235 & 7.825 \\
\hline Bikam & $3.599^{*}$ & 3.989 & 4.216 & 5.833 & 3.965 \\
\hline Telok Intan & 3.323 & 3.033 & 3.142 & 3.867 & $3.022^{*}$ \\
\hline Sitiawan & $5.776^{*}$ & 5.953 & 6.032 & 7.091 & 5.993 \\
\hline Kampar & 2.628 & 2.075 & 2.176 & $1.895^{*}$ & 1.932 \\
\hline
\end{tabular}




\begin{tabular}{cccccc} 
Dungun & 8.135 & 7.892 & 8.419 & 7.931 & $7.753^{*}$ \\
Dura & 8.854 & 8.035 & 8.078 & $7.657^{*}$ & 7.801 \\
Gua Musang & 3.706 & $3.507^{*}$ & 6.093 & 3.566 & 3.742 \\
Bertam & $3.970^{*}$ & 4.551 & 5.425 & 6.910 & 4.44 \\
Sg. Tong & 4.739 & 4.532 & 5.330 & 5.881 & $4.498^{*}$ \\
Chalok & 5.872 & 4.623 & 4.820 & $3.403^{*}$ & 4.311 \\
Dabong & 4.507 & $4.087^{*}$ & 5.408 & 4.648 & 4.327 \\
Sg. Pinang & 4.723 & 4.074 & 4.124 & 4.746 & $3.903^{*}$ \\
Bkt. Bendera & 3.794 & $3.495^{*}$ & 3.831 & 4.449 & 3.549 \\
Baling & $2.258^{*}$ & 2.296 & 2.676 & 4.166 & 2.344 \\
Jeniang Klinik & 4.739 & 4.532 & 5.330 & 5.881 & $4.498^{*}$ \\
Alor Setar & 4.303 & 3.571 & 4.628 & $3.318^{*}$ & 3.653 \\
Kuala Nerang & $5.776^{*}$ & 5.953 & 6.032 & 7.091 & 5.993 \\
\hline
\end{tabular}

"Nilai MRM, ralat kebagusan pemadanan yang terkecil untuk setiap stesen

Sifat takvarians skala bagi 43 buah stesen kajian dikaji lebih lanjut dan anggaran nilai penskalaan eksponen dihitung. Nilai yang diperoleh ini boleh digunakan untuk mendapat nilai ulangan berdasarkan tempoh ulangan, $T$ tahun tertentu. Dengan memilih suatu skala rujukan, sebagai contoh skala harian atau 24 jam, nilai ulangan untuk subskala yang lain yang bersesuaian boleh dianggar berasaskan sifat takvarians skala pada (7). Jadual 5 menunjukkan keputusan untuk $T=50,100$ dan 150 tahun, dengan tempoh 24 jam diletakkan sebagai skala rujukan untuk kesemua stesen kajian yang menepati ciri pengskalaan ringkas seperti keputusan terdahulu.

JADUAL 5. Maklumat taburan terbaik, anggaran parameter taburan, faktor penskalaan dan nilai ulangan berdasarkan data skala 24 jam untuk 41 stesen hujan di Semenanjung Malaysia

\begin{tabular}{ccccccccc}
\hline Stesen hujan & Taburan & \multicolumn{2}{c}{ Parameter } & & $\hat{\alpha}$ & \multicolumn{3}{c}{$\begin{array}{c}\text { Nilai ulangan berdasarkan } T \\
\text { tahun }^{\dagger}\end{array}$} \\
\hline & & & $\hat{\xi}$ & $\hat{\delta}$ & $\hat{\kappa}$ & & 50 & 100 \\
\hline Johor Bahru & GLO & 106.7 & 19.5 & -0.254 & 0.276 & 236.2 & 276.6 & 303.6 \\
Mersing & P3 & 163.4 & 71.5 & 0.947 & 0.361 & 343.4 & 376.9 & 396.0 \\
Endau & GEV & 190.6 & 85.5 & 0.211 & 0.430 & 418.0 & 442.4 & 455.0 \\
Labis & GPA & 46.6 & 77.0 & 0.279 & 0.303 & 230.0 & 246.3 & 254.5 \\
Chin Chin & GPA & 53.5 & 48.1 & 0.556 & 0.148 & 130.2 & 133.3 & 134.7 \\
Sg. Udang & GLO & 94.5 & 15.0 & 0.091 & 0.152 & 143.8 & 151.0 & 155.0 \\
Rompin & GLO & 83.2 & 16.2 & -0.156 & 0.183 & 169.7 & 191.8 & 205.7 \\
Seremban & GEV & 80.9 & 21.4 & 0.121 & 0.166 & 147.5 & 156.5 & 161.4 \\
Sg. Manggis & GEV & 74.5 & 16.2 & -0.125 & 0.149 & 156.1 & 175.4 & 187.5 \\
Semenyih & GLO & 85.1 & 13.3 & -0.189 & 0.208 & 161.9 & 182.8 & 196.4 \\
Kuala Klawang & GLO & 75.3 & 13.6 & -0.322 & 0.181 & 180.8 & 218.3 & 244.3
\end{tabular}




\begin{tabular}{|c|c|c|c|c|c|c|c|c|}
\hline Sg. Kepasing & GLO & 96.5 & 18.2 & -0.021 & 0.227 & 170.4 & 184.4 & 192.6 \\
\hline Ampang & GPA & 66.7 & 60.7 & 0.931 & 0.133 & 130.1 & 131.0 & 131.2 \\
\hline Edinburgh & Gumbel & 83.6 & 22.3 & - & 0.148 & 170.6 & 186.1 & 195.2 \\
\hline Genting Klang & GLO & 95.4 & 15.8 & -0.210 & 0.195 & 190.4 & 217.5 & 235.1 \\
\hline Kuala Sleh & GLO & 88.1 & 11.1 & -0.106 & 0.155 & 141.5 & 153.7 & 161.2 \\
\hline Gombak & GLO & 92.3 & 11.6 & -0.157 & 0.136 & 154.4 & 170.3 & 180.3 \\
\hline Sg. Tua & GEV & 83.0 & 15.0 & -0.122 & 0.163 & 157.9 & 175.5 & 186.5 \\
\hline Pekan & P3 & 188.0 & 110.5 & 1.632 & 0.417 & 496.4 & 564.3 & 603.8 \\
\hline Kalong Tengah & GLO & 97.8 & 14.7 & -0.245 & 0.200 & 193.6 & 223.0 & 242.5 \\
\hline Tanjung Malim & GLO & 98.4 & 16.9 & -0.119 & 0.160 & 182.0 & 201.6 & 213.9 \\
\hline Sg. Bernam & GEV & 89.3 & 16.8 & -0.177 & 0.154 & 183.6 & 208.4 & 224.4 \\
\hline Paya Kangsar & GEV & 76.9 & 21.9 & 0.119 & 0.162 & 145.1 & 154.3 & 159.4 \\
\hline Ulu Tekai & GEV & 83.4 & 42.7 & -0.146 & 0.370 & 307.7 & 363.1 & 398.1 \\
\hline Bikam & GLO & 96.3 & 14.1 & -0.082 & 0.177 & 160.9 & 174.9 & 183.5 \\
\hline Telok Intan & P3 & 91.3 & 28.4 & 1.173 & 0.190 & 165.5 & 180.2 & 188.6 \\
\hline Sitiawan & GLO & 82.4 & 15.3 & -0.148 & 0.128 & 163.0 & 183.2 & 195.9 \\
\hline Kampar & GPA & 80.0 & 47.6 & 0.348 & 0.176 & 181.7 & 189.2 & 192.8 \\
\hline Dungun & P3 & 184.2 & 94.2 & 1.781 & 0.460 & 451.9 & 512.8 & 548.3 \\
\hline Dura & GPA & 70.9 & 196.4 & 0.396 & 0.474 & 461.6 & 486.9 & 498.8 \\
\hline Gua Musang & GEV & 84.4 & 14.6 & -0.280 & 0.209 & 188.0 & 221.7 & 244.6 \\
\hline Bertam & GLO & 96.3 & 18.4 & -0.062 & 0.213 & 177.3 & 194.1 & 204.3 \\
\hline Sg. Tong & P3 & 185.6 & 78.0 & 0.539 & 0.427 & 367.2 & 397.1 & 413.8 \\
\hline Chalok & GPA & 81.2 & 178.9 & 0.476 & 0.450 & 398.8 & 415.2 & 422.6 \\
\hline Dabong & GEV & 103.6 & 34.8 & -0.141 & 0.299 & 284.4 & 328.6 & 356.5 \\
\hline Sg. Pinang & P3 & 139.4 & 51.9 & 0.941 & 0.292 & 269.9 & 294.1 & 308.0 \\
\hline Bkt. Bendera & GEV & 106.7 & 34.5 & 0.094 & 0.285 & 219.4 & 235.6 & 244.5 \\
\hline Baling & GLO & 87.7 & 13.0 & -0.113 & 0.193 & 151.3 & 166.1 & 175.2 \\
\hline Jeniang Klinik & $\mathrm{P} 3$ & 185.6 & 78.0 & 0.539 & 0.427 & 367.2 & 397.1 & 413.8 \\
\hline Alor Setar & GPA & 54.4 & 94.8 & 0.851 & 0.236 & 161.8 & 163.5 & 164.2 \\
\hline Kuala Nerang & GLO & 82.4 & 15.3 & -0.148 & 0.128 & 163.0 & 183.2 & 195.9 \\
\hline
\end{tabular}

${ }^{\dagger}$ Nilai ulangan, $\hat{x}_{d, T}=\left(\frac{d}{d_{o}}\right)^{\alpha} \hat{F}_{d_{o}}^{-1}\left(1-\frac{1}{T}\right)$ dengan $d_{o}=24$ sebagai skala rujukan

Menggunakan skala 24-jam sebagai rujukan serta faktor penskalaan, $\hat{\alpha}$ bagi setiap stesen, nilai-nilai tempoh ulangan mengikut skala yang berbeza dapat dihitung. Rajah 2 dan 3 menunjukkan peta reruang untuk nilai ulangan tempoh 50 dan 200 tahun bagi Semenanjung Malaysia bagi skala 1, 3, 6, 12 dan 24 jam. Pemetaan menunjukkan skala 1 jam menggambarkan corak taburan reruang yang berbeza berbanding skala 3, 6, 12 dan 24 jam bagi kedua-dua tempoh ulangan. Ini menunjukkan bahawa kawasan selatan Semenanjung menerima hujan paling banyak dalam tempoh skala masa yang pendek berbanding skala masa panjang yang mana kawasan timur Semenanjung Malaysia termasuklah di pesisir bahagian Tenggara turut menerima hujan yang lebat. Sebahagian kecil kawasan utara juga mengalami hujan yang lebat seperti ditunjukkan dalam peta pada Rajah 2 dan 3. 

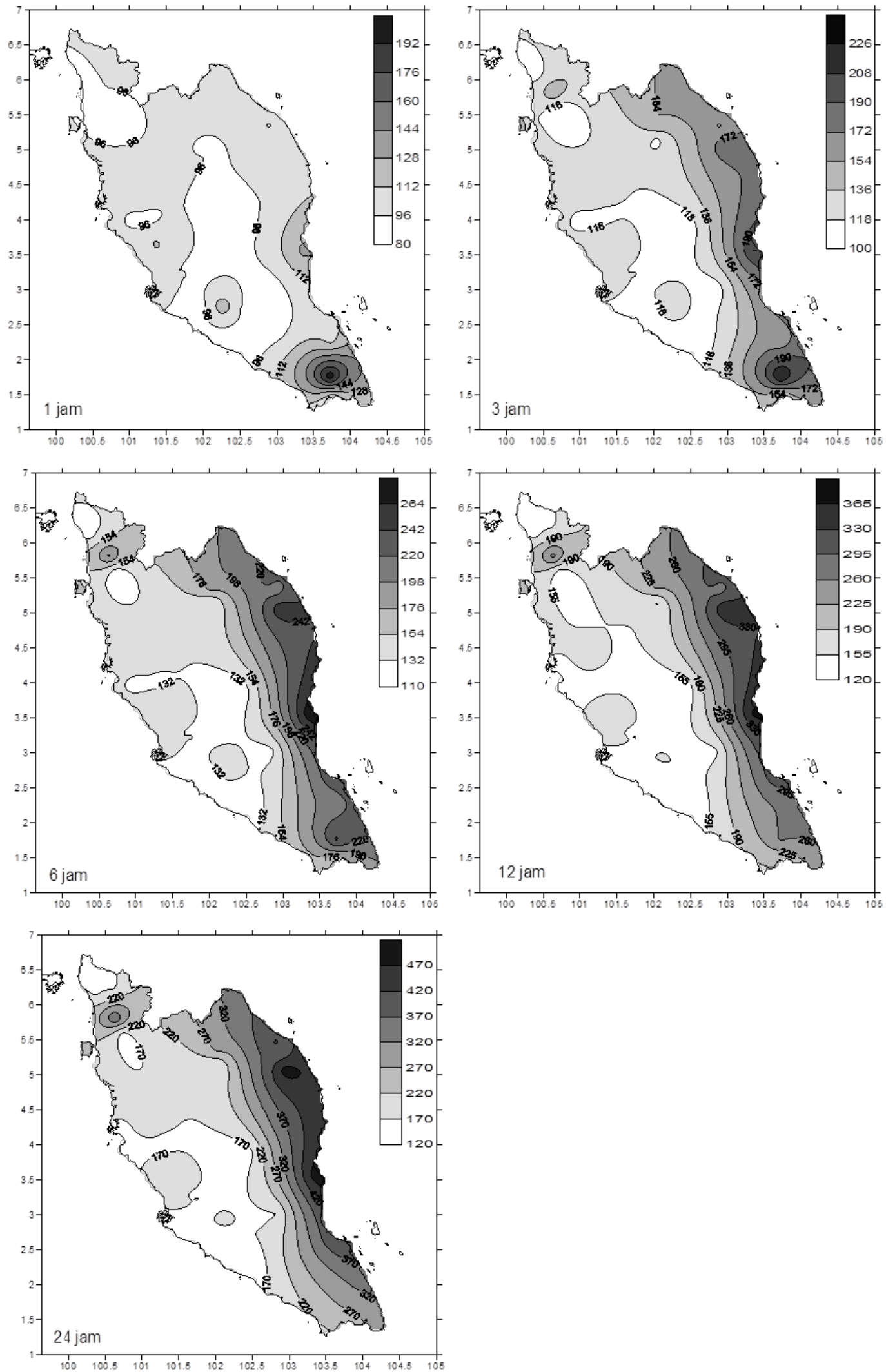

RAJAH 2. Peta Reruang untuk Nilai Ulangan tempoh 50 Tahun bagi Semenanjung Malaysia 

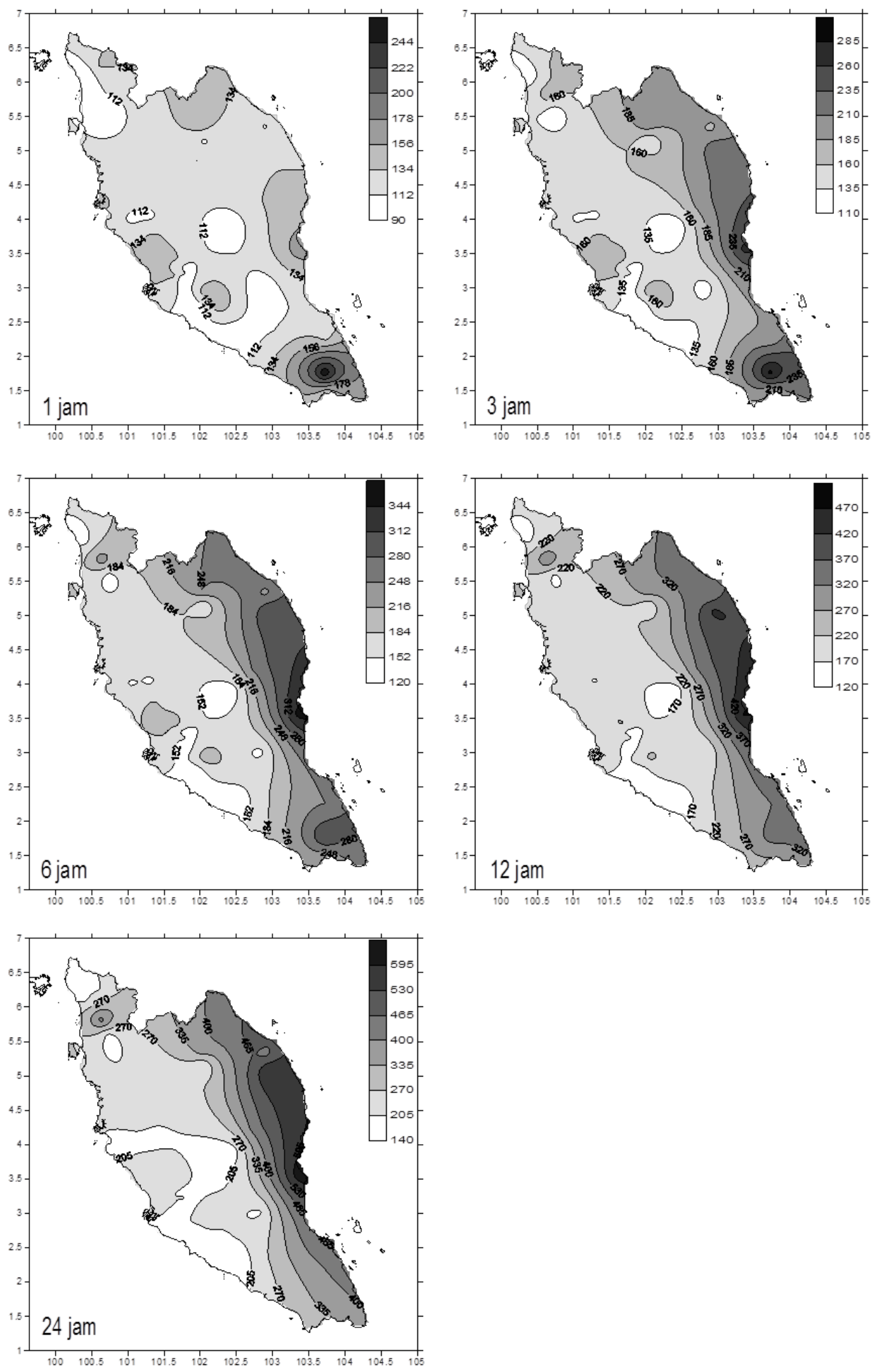

RAJAH 3. Peta Reruang untuk Nilai Ulangan tempoh 200 Tahun bagi Semenanjung Malaysia 


\section{KESIMPULAN}

Di dalam kajian ini, data hujan maksimum dalam pelbagai skala masa dari 43 buah stesen cerapan hujan di Semenanjung Malaysia telah dikaji untuk menilai ciri penskalaan yang sesuai di setiap stesen. Hasil menunjukkan bahawa ciri penskalaan ringkas adalah jenis pengskalaan yang sesuai bagi majoriti stesen kajian. Model penskalaan ringkas yang diperoleh membolehkan pengkaji menskalakan data yang diperoleh dalam skala yang besar (contoh 24-jam) ke skala yang lebih kecil (contoh 1-jam) dalam kes dengan data dalam skala kecil sukar diperoleh. Maklumat ini seterusnya dapat digunakan dalam pembinaan IDF yang merupakan rujukan utama dalam penyediaan infrastruktur berkaitan hidrologi. Hasil daripada kajian ini merupakan kajian pertama yang diterbitkan di Malaysia melibatkan penskalaan masa dan boleh digunakan sama ada pada skala masa yang lebih rendah (penskalan ke bawah) atau tinggi (penskalaan ke atas) dengan mengambil kira taburan statistik yang terbaik bagi memperihalkan hujan maksimum di sesebuah stesen tertentu. Daripada kajian kami, walaupun terdapat beberapa artikel yang telah ditulis mengenai penerapan konsep penskalaan dalam beberapa kajian di Malaysia, namun konteks dan kaedah yang digunakan adalah berbeza kerana kajian-kajian tersebut tertumpu kepada penskalaan data satelit (Mahmud et al. 2018; Omotosho et al. 2013, Soo et al. 2020) atau data daripada model iklim dunia (Hamidon et al. 2019; Hassan \& Harun 2012; Hassan et al. 2019; Noor \& Ismail 2018). Keputusan daripada kajian ini adalah penting dari segi penerapan memandangkan pentaabiran statistik dapat dibuat dengan menggunakan sifat penskalaan ringkas hujan maksimum yang membolehkan anggaran nilai data daripada skala yang kecil yang lazimnya sukar diperoleh berbanding dengan data hujan maksimum dalam skala yang besar.

\section{PENGHARGAAN}

Penghargaan kepada Universiti Kebangsaan Malaysia (UKM) dan Kementerian Pengajian Tinggi, Malaysia untuk geran FRGS/1/2015/ST06/UKM/02/2 serta Jabatan Parit dan Saliran (JPS), Malaysia untuk data hujan yang diberikan.

\section{RUJUKAN}

Agbazo, M., Koton'Gobi, G., Kounouhewa, B., Alamou, E. \& Afouda, A. 2016. Estimation of IDF curves of extreme rainfall by simple scaling in Northern Oueme Valley, Benin Republic (West Africa). Earth Sciences Research Journal 20(1): D1-D7.

Bara, M., Gaal, L., Kohnova, S., Szolgat, J. \& Hlavcova, K. 2010. On the use of the simple scaling of heavy rainfall in a regional estimation of IDF curves in Slovakia. Journal of Hydrology and Hydromechanics 58(1): 49-63.
Blöschl, G. \& Sivapalan, M. 1995. Scale issues in hydrological modelling: A review. Hydrological Processes 9(3-4): 251290.

Bougadis, J. \& Adamowski, K. 2006. Scaling model of rainfall intensity-duration-frequency relationship. Hydrological Processes 20: 3747-3757.

Burlando, P. \& Rosso, R. 1996. Scaling and multi-scaling models of depth-duration-frequency curves for storm precipitation. Journal of Hydrology 187(1/2): 45-64.

Ceresetti, D., Molinié, G. \& Creutin, J.D. 2010. Scaling properties of heavy rainfall at short duration: A regional analysis. Water Resources Research 46(9): 1-12.

De Michele, C., Kottegoda, N.T. \& Rosso, R. 2002. IDAF (Intensity-duration-area frequency) curves of extreme storm rainfall: A scaling approach. Water, Science \& Technology 45(2): 83-90.

Deni, S.M., Jamaludin, S., Zin, W.Z.W \& Jemain, A.A. 2009. Trends of wet spells over Peninsular Malaysia during monsoon seasons. Sains Malaysiana 38(2): 133-142.

Dubrulle, B., Graner, F. \& Sornette, D. 1997. Scale Invariance and Beyond, EDP Sciences, Les Houches Workshop, Les Ulis, France, 10-14 March.

Eli, A., Shaffie, M. \& Zin, W.Z.W. 2012. Preliminary study on bayesian extreme rainfall analysis: A case study of Alor Setar, Kedah, Malaysia. Sains Malaysiana 41(11): 1403-1410.

Ellouze, M. \& Abida, H. 2008. Regional flood frequency analysis in Tunisia: Identification of regional distributions. Water Resources Management 22(8): 943-957.

Gupta, V.K. \& Waymire, E. 1990. Multiscaling properties of spatial and river flow distributions. Journal of Geophysical Research: Atmospheres 95(D3): 1999-2009.

Hamidon, N., Harun, S., Sunar, N.M., Hamid, N.H.A., Muhamad, M.S., Harun, H., Ali, R., Awang, M., Rahman, M.A.A., Ahmad, F., Musa, K., Yusof, F.M. \& Mustafa, M.S.S. 2019. Prediction of future climate change for rainfall in the upper Kurau River Basin, Perak using statistical downscaling model (SDSM). Civil Engineering and Architecture 7(6A): $33-42$.

Hanawi, S.A., Zin, W.Z.W., Jemain, A.A \& Ahmad, R. 2011. Fenomena kehujanan di Semenanjung Malaysia berdasarkan Indeks Kerpasan Piawai. Sains Malaysiana 40(11): 1277-1284.

Hassan, Z. \& Harun, S. 2012. Application of statistical downscaling model for long lead rainfall prediction in Kurau River catchment of Malaysia. Malaysian Journal of Civil Engineering 24(1): 1-12.

Hassan, Z., Mansor, M.F.M. \& Kamarudzaman, A.N. 2019. Rainfall projection corresponding to climate scenarios based on statistical down-scaling model over Perlis, Malaysia. Journal of Engineering Research and Education 11: 9-14.

Hosking, J.R.M. 1990. L-Moments: Analysis and estimation of distributions using linear combinations of order statistics. Journal of the Royal Statistical Society. Series (B) 52(1): 105-124.

Langousis, A., Carsteanu, A.A. \& Deidda, R. 2013. A simple approximation to multifractal rainfall maxima using a generalized extreme value distribution model. Stochastic Environmental Research and Risk Assessment 27: 1525-1531. 
Lovejoy, S. \& Schertzer, D. 1985. Generalized scale invariance in the atmosphere and fractal models of rain. Water Resources Research 21(8): 1233-1250.

Mahmud, M.R., Hashim, M., Matsuyama, H., Numata, S. \& Hosaka, T. 2018. Spatial downscaling of satellite precipitation data in humid tropics using a site-specific seasonal coefficient. Water 10(4): 409.

Menabde, M., Seed, A. \& Pegram, G. 1999. A simple scaling model for extreme rainfall. Water Resources Research 35(1): 335-339.

Noor, M. \& Ismail, T. 2018. Downscaling of daily average rainfall of Kota Bharu Kelantan, Malaysia. Malaysian Journal of Civil Engineering 30(1): 13-22.

Omotosho, T.V., Mandeep, J.S., Abdullah, M. \& Adediji, A.T. 2013. Distribution of one-minute rain rate in Malaysia derived from TRMM satellite data. Annals of Geophysics 31(11): 2013-2022.

Rahman, M.M. 2015. Development of rainfall intensityduration-frequency relationships from daily rainfall data for the major cities in Bangladesh based on scaling properties. International Journal for Scientific Research \& Development 3(8): 627-631.

Rana, A., Bengtsson, L., Olsson, J. \& Jothiprakash, V. 2013. Development of IDF-curves for tropical India by random cascade modeling. Hydrology and Earth System Sciences Discussions 10(4): 4709-4738.

Rodriguez-Iturbe, I., Gupta, V.K. \& Waymire, E. 1984. Scale considerations in the modeling of temporal rainfall. Water Resources Research 20(11): 1611-1619.

Sivapalan, M. \& Blöschl, G. 1998. Transformation of point rainfall to areal rainfall: Intensity-duration-frequency curves. Journal of Hydrology 204(1-4): 150-167.

Soo, E.Z.X., Jaafar, W.Z.W., Lai, S.H., Othman, F., Elshafie, A., Islam, T., Srivastava, P. \& Hadi, H.S.O. 2020. Evaluation of bias-adjusted satellite precipitation estimations for extreme flood events in Langat river basin, Malaysia. Hydrology Research 51(1): 105-126.
Syafrina, A.H., Zalina, M.D. \& Juneng, L. 2015. Historical trend of hourly extreme rainfall in Peninsular Malaysia. Theoretical and Applied Climatology 120(1-2): 259-285.

Veneziano, D. \& Langousis, A. 2010. Scaling and fractals in hydrology. In Advances in Data-Based Approaches for Hydrologic Modeling and Forecasting, edited by Sivakumar, B. \& Berndtsson, R. Singapore: World Scientific Publishing Company. pp. 107-243.

Veneziano, D. \& Furcolo, P. 2002. Multifractality of rainfall and scaling of intensity-duration-frequency curves. Water Resources Research 38(12): 42-1.

Vogel, R.M. \& Fennessey, N.M. 1993. L-moment diagrams should replace product moment diagrams. Water Resources Research 29(6): 1745-1752.

Westra, S., Fowler, H.J., Evans, J.P., Alexander, L.V., Berg, P., Johnson, F., Kendon, E.J., Lenderink, G. \& Roberts, N.M. 2014. Future changes to the intensity and frequency of short-duration extbreme rainfall. Reviews of Geophysics 52(3): 522-555.

Yu, P.S, Yang, T.C. \& Lin, C.S. 2004. Regional rainfall intensity formulas based on scaling property of rainfall. Journal of Hydrology 295(1): 108-123.

Zin, W.Z.W., Jemain, A.A., Ibrahim, K., Jamaludin, S. \& Deni, S.M. 2009. A comparative study of extreme rainfall in Peninsular Malaysia: With reference to partial duration and annual extreme series. Sains Malaysiana 38: 751-760.

Jabatan Sains Matematik

Fakulti Sains dan Teknologi

Universiti Kebangsaan Malaysia

43600 UKM Bangi, Selangor Darul Ehsan

Malaysia

*Pengarang untuk surat-menyurat; email: w_zawiah@ukm. edu.my

Diserahkan: 19 Julai 2018

Diterima: 16 April 2020 